\begin{tabular}{|l|l|}
\hline $\begin{array}{l}\text { Postprint } \\
\text { Version }\end{array}$ & 1.0 \\
\hline Journal website & $\underline{\text { http://www.sciencedirect.com/science/article/pii/S0168851011002247 }}$ \\
\hline Pubmed link & $\underline{\text { http://www.ncbi.nlm.nih.gov/pubmed/22079753 }}$ \\
\hline DOI & $10.1016 /$ j.healthpol.2011.10.011 \\
\hline
\end{tabular}

This is a NIVEL certified Post Print, more info at http://www.nivel.eu

\title{
Do rheumatoid arthritis patients have equal access to treatment with new medicines? Tumour necrosis factor- alpha inhibitors use in four European countries
}

\author{
JOËLLE M. HOEBERT ${ }^{\mathrm{A}}$, AUKJE K. MANTEL-TEEUWISSE ${ }^{\mathrm{A}}$, LISET VAN DIJK ${ }^{\mathrm{B}}$, JOHANNES W.J. BiJLSMA ${ }^{\mathrm{C}}$, \\ HUBERT G.M. LEUFKENS ${ }^{A}$ \\ ${ }^{a}$ Utrecht Institute for Pharmaceutical Sciences, Division of Pharmacoepidemiology and Clinical \\ Pharmacology, Utrecht University, The Netherlands \\ ${ }^{b}$ NIVEL, Netherlands Institute for Health Services Research, Utrecht, The Netherlands \\ ${ }^{c}$ Department of Rheumatology \& Clinical Immunology, University Medical Center, Utrecht, The Netherlands
}

\begin{abstract}
Purpose: To explore the use of the biological tumour necrosis factor alpha (TNFalpha) inhibitors used in the treatment of rheumatoid arthritis as a measure of access to treatment with new medicines. In addition, characteristics both related to national health systems and spending will be assessed to explore possible differences in international utilisation.

Methods: Data from four European countries were included: Ireland, The Netherlands, Norway and Portugal. Annual utilisation rates of TNFalpha inhibitors (2003-2007) were expressed as defined daily doses (DDDs)/1000 inhabitants/day. Qualitative data such as country characteristics, national health policy characteristics, guidelines were obtained from the literature. In addition, interviews were held with leading rheumatologists of each country to put obtained results into (cultural) context.

Results: Utilisation of TNFalpha inhibitors varied widely from 0.32 (Portugal) to 1.89 (Norway) DDDs/1000 inhabitants/day (2007). A major driver for the utilisation of TNFalpha inhibitors seemed to be the country's total health expenditure $(\mathrm{R} 2=0.81)$. When the use of TNFalpha inhibitors became more established, the association seemed stronger. Differences in health expenditure were nevertheless not the only determinant of usage. Cultural aspects such as difference in recognition of guidelines also come into play when looking at differences in TNFalpha utilisation between countries.

Conclusions: The prospects of patients receiving TNFalpha inhibitor treatment depend on the country where they are living. In case uniformity of management and treatment would be considered to provide health benefits, the extent and the causes of variation should feature prominently on future public health agendas.
\end{abstract}




\section{INTRODUCTION}

The introduction of biologicals for the treatment of rheumatoid arthritis (RA) marked a major step forward in the management of this disease and created a paradigm shift in the treatment of RA. Biologicals are now being prescribed earlier and more often as combination therapy than five years ago [1], [2], [3] and [4]. Remission of disease is now the primary therapeutic aim which can be achieved through intensive treatment strategies [5]. However, biologicals for treating RA are expensive; annual treatment costs for biologicals in the first year range from about $€ 13.500$ to $€ 15.000$ [6] and [0035]. Treatment costs have become an important concern associated with the use of these biologicals. Western European health care systems aim to achieve optimal health and economic outcomes for society as a whole as well as for the individual patient. Governments strive to ensure affordable access to a wide range of prescription medicines equitably across all areas and to all patients [8]. However, individual governments may take different measures to achieve this goal, which may result in variable access to these biologicals.

Variation in access to medicines is seen in practice, even within a single country. An Australian study reported that within a country, those in equal need may not have equal opportunities to access rheumatologic services [9]. Geographical variation in access to biologicals ('postal code prescribing') has also been identified in the United Kingdom [9] and [10]. A recent report on international variation in medicines usage commissioned by the UK Department of Health, examined how medicines usage varied between countries. For the disease RA, the UK usage of biologicals ranked relatively low compared to 13 other European Union (EU) countries [11]. The reasons for these variations were diverse and sometimes difficult to establish. Differences in health spending and systems did not appear to be strong determinants of usage, but clinical culture and attitudes towards treatment did. For example, the use of biologicals in Australia roughly correlated with the per capita ratio of rheumatologists, and this varied considerably between geographical regions [9]. On the other hand, another study trying to explain the variations in uptake of biologicals did note differences in national income (as measured by gross domestic product (GDP)) as a possible explanation [12]. The relative impact of each explanatory factor is likely to differ among systems [0035] , [13] and [0070] .

While the authorisation of biologicals is centralised by the European Medicines Agency (EMA) and the clinical evidence base available to the national societies issuing clinical guidelines is largely the same, the management of diseases as well as pharmaceutical policies and therefore the usage of biologicals may vary widely across Europe. Building on previous reports on access to treatment in RA, the objective of this study was to further explore the use of the biological tumour necrosis factor alpha (TNFalpha) inhibitors used in the treatment of RA as a measure of access to treatment with new medicines by studying national health systems and spending characteristics. In addition, we aimed to add opinions from key leading rheumatologist to put the obtained results into (cultural) perspective.

\section{MethodOLOGY}

To enable comparisons of medicines utilisation between countries, datasets with a comparable structure need to be available. Factors that should also be taken into consideration, such as regulatory and budgetary constraints, reimbursement policies and cultural factors should all be well documented. In addition, we aimed to select countries that were similar in size, but also representing a certain geographical and variation in gross domestic product and health expenditures that exists within Europe. Based on these criteria, four countries were selected, namely Portugal, Ireland, Norway and The Netherlands.

\subsection{Regulatory situation}

In Europe until 2008, three TNFalpha inhibitors, infliximab (Remicade ${ }^{\circledR}$ ), etanercept (Enbrel ${ }^{\circledR}$ ) and adalimumab (Humira ${ }^{\circledR}$ ), had been approved by the Committee for Medicinal Products for Human Use (CHMP) [0075] , [16], [0085] and [0090]. Although not all TNFalpha inhibitors were initially approved for RA, by 2007 all three TNFalpha inhibitors have had several approved indication extensions including RA, see Table 1. All of these TNFalpha inhibitors were included in the present study. 


\section{[TABLE 1]}

\subsection{Population and disease characteristics, national health policy characteristics and budgetary constraints}

Population and disease characteristics (e.g. population size, prevalence of RA), specific national health policy characteristics, such as reimbursement restrictions and national guidelines, and data on budgetary constraints, such as GDP, total health expenditures (THE) and total pharmaceutical expenditures (TPE) related to these countries were retrieved from various public sources [0035] , [0095] , [20], [0105] , [0110] and [0115] . Price information was retrieved from GÖG PPI System 2011 and included ex-factory prices (per unit) of all available package sizes, as of October 2004 and June 2007.

Four key leading rheumatologists of each participating country were interviewed in 2009 to comment on the differences seen in utilisation according to the cultural context and clinical attitude towards TNFalpha inhibitors. The interviewed rheumatologists were Professor J.A.P. da Silva (Portugal), Professor B.A.C. Dijkmans (The Netherlands), Professor T.K. Kvien (Norway) and Professor D.J. Veale (Ireland). They all play an active role in their national societies of rheumatology and in the European League Against Rheumatism (EULAR). Interviews followed a semi-structured guide to allow adaption to the background of the rheumatologists and country-specific circumstances and inclusion of additional relevant information. The interviews covered the following three main themes: hurdles to perform an adequate treatment of RA, opinions on current treatment options and future directions of RA treatment. The information gathered in these interviews has been included in the result and discussion section, and served as country specific examples.

\subsection{Utilisation data}

Collection of TNFalpa inhibitors utilisation data was realized with support of the European PILLs (PostInnovation Learning Cycle for Pharmaceuticals) network [8], an international research network (network members working in academic institutions or at national health agencies) involved in the study of the effects of pharmaceutical policies in medicines use. Table 2 shows an overview of the sources used for the extraction of the utilisation data. For Norway and Portugal, sales data from the Norwegian Institute of Public Health and IMS Health, respectively, were retrieved. A combination of sales and claim data were used to cover the utilisation for The Netherlands and Ireland. The two databases that provided data for The Netherlands were the GIP database (ambulatory data) and Farminform (hospital data), and for Ireland the Health Service Executive (ambulatory data) and IMS Health (hospital data).

\section{[TABLE 2]}

TNFalpha utilisation rates were calculated as a measure of uptake in the health system. The anatomical therapeutic chemical (ATC)/defined daily dose (DDD) methodology was chosen as method for presenting drug utilisation data [24]. The DDD is a dosage measure determined by the World Health Organization (WHO) and is based on the assumed average daily maintenance dose for its main indication use in adults [25]. This common classification system and common unit of measurement to express volume of consumption allows the study of trends in medicines consumption [26]. Utilisation data were obtained for products with ATC codes L04AB01 (etanercept), L04AB02 (infliximab) and L04AB04 (adalimumab) and covered the period 2003-2007. For infliximab, the DDD is $3.75 \mathrm{mg}$, for etanercept $7 \mathrm{mg}$ and for adalimumab $2.9 \mathrm{mg}$. DDDs used in this study are the DDDs for the main indication (RA) and resemble the usual dose for RA as reflected in the current national guidelines (e.g. the DDD of etanercept is $7 \mathrm{mg}$ and the usual dose for RA is $50 \mathrm{mg}$ weekly) [0125] and [0135] . The data were presented on an aggregated level in DDDs per year or in DDDs per 1000 inhabitants per day. In order to achieve collection of consistent and comparable data, the representative of each participating country was required to provide the data by means of a specially developed, well defined, standardized questionnaire.

\subsection{Data analysis}


Utilisation rates in DDDs/1000 inhabitants/day were calculated using the mid-year number of persons covered by a data source, or the mid-year population of a country according to the national statistics agency. For The Netherlands, inpatient data were only available for the years 2006-2008 whereas outpatient data were available for the period 2003-2008. Since the ratio between the in- and outpatient use for 2006-2008 was relative constant (1.65, range 1.59-1.69), this ratio was also used to calculate the missing inpatient use for the years 2003-2005.

Ratios were calculated (with The Netherlands as reference, ratio $=1.00$ ) to express differences in exfactory prices of similar formulations between countries. Norwegian Krones (NOK) were converted to euro's using the exchange rate for 2004: 8.3604 and for 2007: 7.8306.

Correlation were estimated for associations between total health expenditure per capita in US\$, purchasing power parity (PPP) and utilisation of TNFalpha inhibitors in DDDs/1000 inhabitants/day between 2003 and 2007 (except for Portugal, data available between 2003 and 2006).

\section{RESULTS}

\subsection{Utilisation data}

Total national utilisation levels varied between the four countries (Fig. 1). In 2007, utilisation of all TNFalpha inhibitors for all diagnoses ranged from 0.32 DDDs/1000 inh/day for Portugal to 1.89 DDDs/1000 inh/day for Norway. An increase in use over time could be demonstrated for all countries. Ireland had a relative high consumption of etanercept (0.46 DDDs/1000 inh/day for 2007) compared to infliximab and adalimumab (both 0.10 DDDs/1000 inh/day in 2007), but compared to the other countries, a low use of infliximab. Portugal on the other hand, had a relatively high consumption of infliximab. In 2007, the consumption of infliximab was $0.22 \mathrm{DDDs} / 1000 \mathrm{inh} /$ day versus $0.04 \mathrm{DDDs} / 1000 \mathrm{inh} /$ day and 0.07 DDDs/1000 inh/day for adalimumab and etanercept, respectively. The Netherlands and Norway had a more or less similar pattern of consumption. In both countries infliximab was the most frequently used TNFalpha inhibitor, closely followed by etanercept and finally adalimumab.

\section{[FIGURE 1]}

\subsection{Regulatory situation}

The time lag between marketing authorisation and the market launch in the four countries was limited to several months, see Table 3. Dates of availability of etanercept, adalimumab and infliximab did not differ much between the countries.

\section{[TABLE 3]}

\subsection{Population and disease characteristics, national health policy characteristics and budgetary constraints}

The population characteristics of the four countries are also shown in Table 3.

The prevalence of adult RA did not vary much, ranging between 0.49 for The Netherlands to 0.56 cases per 100 inhabitants for Norway.

In all countries the use of infliximab is limited to hospitals because of the intravenous administration route. The decision to start treatment with etanercept and adalimumab is made by the treating rheumatologists but may be continued in the outpatient setting, with the exception of Portugal, where until December 2007 the hospitals were the exclusive centres for TNFalpha inhibitor therapy. Outpatient distribution of etanercept and adalimumab in Norway and Ireland is solely done by pharmacists in community pharmacies. In The Netherlands, the outpatient distribution is done via two channels; pharmacies and specialised distributions centres. These distributions centres receive the orders through the Internet or via the hospitals whereas the products are delivered by mail or courier service. Patients should have active RA to receive their medication in this manner. 
There are minimal varying views of what constitutes appropriate use between the national guidelines for the use of biological disease-modifying antirheumatic drugs (DMARDs) in the treatment of RA. The (current) general consensus among these guidelines is that TNFalpha inhibitors should be started after 3 months following confirmed diagnosis of RA and failure of treatment with usually one DMARD, mostly methotrexate (MTX; see Table 3).

Between 2003 and 2007, Norway had the highest GDP per capita and spent more money on health care on a per-capita basis than Ireland, The Netherlands and Portugal.

Collected ex-factory price data for 2004 and 2007 (see Table 3) show a homogenous picture between the four countries. The only exception is adalimumab in Portugal, which is more expensive. The price of this specific TNFalpha inhibitor may have led to limited access. Reimbursement decision dates do not show a substantial difference between the four countries. Except for Norway, no changes related to reimbursement occurred during the study period. In Norway, as of June 1st, 2006, the use of TNFalpha inhibitors is financed via the Norwegian hospitals. The Norwegian Medicines Agency is not involved in reimbursement decisions. In this way both infliximab and adalimumab/etanercept are paid for from the same hospital budget, but expenses are also covered within the Diagnosis Related Groups (DRG) system, and the drugs have different DRG weights. The system with DRG weights is also different for home based and hospital based medications. Some differences existed in the reimbursement regulations between the countries (September 2009). With the exception of Ireland (co-payment depends on medical scheme), the outpatient use of TNFalpha inhibitors is fully reimbursed provided relevant reimbursement conditions are met. Restrictions are related to specific indications and trial of DMARD. In The Netherlands, TNFalpha inhibitors are fully reimbursed after failure of at least two DMARDs, of which one is MTX. This is in contradiction with the guidelines, where TNFalpha inhibitors may be initiated after failure of one DMARD. In all countries TNFalpha inhibitors were fully reimbursed for inpatient use.

Over time and in all countries treatment of RA has evolved into more intensive strategies (interview data). Biologicals are being prescribed earlier, a shift in the use of DMARDs has occurred and more combination therapy is used on the basis of evidence of clinical efficacy. The increase in the use of TNFalpha inhibitors over time may also be explained by the fact that rheumatologists have become more demanding when it comes to treatment outcomes. Whereas in the past a maximum of 3-4 flares per year was seen as acceptable, nowadays 1 flare per year is considered as such, which can be realized by the use of TNFalpha inhibitors. This explains the increase in use of TNFalpha inhibitors over time but does not explain the differences seen in utilisation between the countries.

Overall, the above mentioned findings do not show unequivocally that system characteristics such as launch dates, guidelines and reimbursement restrictions exert a strong determinative effect on the variation in the level of TNFalpha inhibitor utilisation. Fig. 2 shows the overall correlation between the utilisation of TNFalpha inhibitors and health expenditure per capita over time $\left(R^{2}=0.81\right)$. Virtually the same correlation was found when looking at gross domestic product. Although Norway has a relative low total pharmaceutical expenditure, a strong increase (three fold) was found for the utilisation of TNFalpha inhibitors over time, a pattern also seen for The Netherlands but not for Ireland and Portugal. Fig. 3 clearly shows that over time and with the advance of TNFalpha inhibitors as primary line of treatment, the correlation with available health budgets (total health expenditure per capita) becomes more pronounced, approaching 1.0.

\section{[FIGURE 2, FIGURE 3]}

As based on the interviews the following additional observations for the four countries were made:

- $\quad$ Portugal has only a limited number of hospitals with rheumatology clinics (in 2007, twelve hospitals). As a consequence access to RA therapy is more difficult for patients living in rural areas, far away from hospitals. In addition, the prescription of TNFalpha inhibitors is restricted to rheumatologists (and internists) in hospitals only (until 2007).

- $\quad$ Ireland has no limited access to rheumatologists in hospitals but regional differences in access to treatment in hospitals is seen as the budget spent on TNFalpha inhibitors is an individual hospital decision. 
- $\quad$ The Netherlands has unrestricted access to rheumatologists. The biggest barrier to TNFalpha treatment is the budget cap for hospitals. Access to outpatient treatment is limited through strict guidelines and reimbursement regulations.

- $\quad$ Norway has liberal access to TNFalpha inhibitor treatment. Strategies to control costs of biological agents and to limit prescribing include (i) a central tender system - leading to a cost-based recommendation, (ii) consultation of a colleague before initiating TNFalpha inhibitor treatment in an individual patient and (iii) recommendations for use issued by the Directorate of Health.

Other potential causes of variation in TNFalpha utilisation grouped according to common themes raised during the interviews are shown in Table 4.

\section{[TABLE 4]}

\section{Discussion}

This study indicates that there is a large variation in the utilisation of TNFalpha inhibitors between Portugal, The Netherlands, Ireland and Norway. Having approximately the same degree of utilisation in 2003, until 2007 rates tripled in Portugal, increased 6-fold in Ireland and over 10-fold in The Netherlands. The prospect of patients receiving TNFalpha inhibitor treatment therefore depends on the country where they are living. A major driver for the utilisation of TNFalpha inhibitors at the national level seems the country's total health expenditure and national income, as measured by GDP. Explaining this variance in the level of TNFalpha utilisation between the four studied countries should also include factors acting at the level of financing and regulation of the health system, and procedures around reimbursement policies: whether (TNFalpha inhibitor) treatment is being reimbursed. The decision to expand the prescription of TNFalpha inhibitors to rheumatologists in private clinics in Portugal, emphasizes the role of national priority setting (interview data). The interviewed rheumatologists also addressed the importance of health system factors. They stated that a number of other factors, such as access to rheumatologists and levels of recognition of guidelines should also be taken into account when trying to further explain the differences in access to treatment with TNFalpha inhibitors. In addition, this study shows that when TNFalpha utilisation in clinical practice becomes more established, the health expenditures per capita become stronger associated with the total amount used.

This study shows how individual countries are struggling in achieving a balance between equal access to new expensive medicines, such as TNFalpha inhibitors and cost containment which shows the difficulties reconciling the concept of uniform registration and uniform management. The situation in Norway may serve as an example. Consultation of a colleague before initiating a TNFalpha inhibitor in Norway is seen as a valuable tool, as patients have become more demanding and start pushing the rheumatologist to prescribe TNFalpha inhibitors. The above underlines that prescribers of these (new and expensive) medicines should adhere to the guidelines, while regulators and policy makers at the same time should enforce the rules, meaning that non-adherence to guidelines should be discouraged. Options for enforcing such rules could include defining quality indicators for treating physicians or administrative requirements before reimbursement (e.g. physician should sign statement that reimbursement restrictions are met).

Some limitations of our data should be noted. The DDD is only a technical expedient and not necessarily equal to the actual use in clinical practice. However, based on the information from the interviews there are no reasons to assume that there were substantial differences in prescribing dosages. In addition, the figure will over-represent TNFalpha inhibitors usage in RA, as these biologicals are not prescribed exclusively for RA; although this is the major indication for use so far according to our experts. All interviewed rheumatologists play an active role in their national societies of rheumatology and in the European League Against Rheumatism (EULAR). We therefore feel that they will be able to provide a fair representative view of rheumatologists in their respective countries.

We only looked at the national level and did not take regional and inter-practice variation into consideration. The studies conducted in Australia and the UK show that access to and use of biological treatment may show large regional variability, for example, depending on policy and budget considerations of individual hospitals or insurance companies or the number of rheumatologist in a specific region [9] and 
[10]. This was also confirmed for Portugal in our study. The high correlations found in this study are also due to the fact that we used highly aggregated data (causing 'ecological fallacy').

Another limitation is that the data sources used in this study consisted of claims and sales data. Therefore, our results may have been influenced by differences between reimbursement and utilisation within countries or by differences by the location of data collection (public pharmacy, wholesalers or both). Nevertheless, double counting or extrapolation corrections are constant factors within a database and will not influence the trend over time of TNFalpha utilisation as shown. This also indicates that there is a need for a harmonised method of data collection on the utilisation of biologicals within Europe. Unfortunately, data were not available per age category in all countries. Therefore, adjustment for the slight differences in age structure of the four countries (Ireland having the youngest population, Portugal the oldest population) was not done [28]. Finally, the included countries constitute a selection of smaller and medium sized European member states. They differed with respect to their geographical position, GDP and health expenditure thereby providing insights into the extent of variation that exists within Europe (range of total health expenditure per capita (US\$, purchasing power parity) of 20 European countries varied from 1035 US\$ for Poland to 4763 US\$ for Norway (2007)).

In conclusion this study shows that not all European patients do have equal access to important medicines in the treatment of RA. The utilisation of TNFalpha inhibitors is positively correlated with total health expenditure per capita within a country. However, although total health expenditure is seen as the major driver for the differences seen in the utilisation of TNFalpha inhibitors, other factors, acting at the level of financing and regulation of the health system, and issues around reimbursement policies, are also likely to play a role in explaining international variation. In case of evidence-based treatment of RA, the causes of variation should feature prominently on future public health agendas.

\section{COMPETING INTERESTS STATEMENT}

The authors JMH, AKM, LD, JWJB, HGML declared no conflicts of interest.

\section{ACKNOWLEDGEMENTS}

The authors would like to thank the following persons for the contributions through interviews, in alphabetical order: Professor B.A.C. Dijkmans (The Netherlands), Professor T.K. Kvien (Norway), Professor J.A.P. Da Silva (Portugal) and Professor D. J. Veale (Ireland).

\section{REFERENCES}

[1] F. Pucino, P.T. Harbus and R. Goldbach-Mansky, Use of biologics in rheumatoid arthritis: where are we going?. American Journal of Health-System Pharmacy, 6318 Suppl. 4 (2006), pp. S19-S41.

[2] Y.P. Goekoop-Ruiterman, J.K. de Vries-Bouwstra, C.F. Allaart, D. van Zeben, P.J.S.M. Kerstens and J.M.W. Hazes, et al. Comparison of treatment strategies in early rheumatoid arthritis: a randomized trial. Annals of Internal Medicine, 1466 (2007), pp. 406-415.

[3] T. Mottonen, P. Hannonen, M. Leirisalo-Repo, M. Nissilä, H. Kautiainen and M. Korpela, et al. Comparison of combination therapy with single-drug therapy in early rheumatoid arthritis: a randomised trial, FIN-RACo trial group. Lancet, 3539164 (1999), pp. 1568-1573.

[4] S.M. Verstappen, M.F. Bakker, A.H.M. Heurkens, M.J. van der Veen, A.A. Kruize and M.A. Geurts, et al. Adverse events and factors associated with toxicity in patients with early rheumatoid arthritis treated with methotrexate tight control therapy: the CAMERA study. Annals of the Rheumatic Diseases, 696 (2009), pp. 1044-1048.

[5] J.S. Smolen, R. Landewé, F.C. Breedveld, M. Dougados, P. Emery and C. Gaujoux-Viala, et al. EULAR recommendations for the management of rheumatoid arthritis with synthetic and biological diseasemodifying antirheumatic drugs. Annals of the Rheumatic Diseases, 696 (2010), pp. 964-975.

[6] W. Kievit, E.M. Adang, J. Fransen, H.H. Kuper, M.A. van de Laar and T.L. Jansen, et al. The effectiveness and medication costs of three anti-tumour necrosis factor alpha agents in the treatment of rheumatoid arthritis from prospective clinical practice data. Annals of the Rheumatic Diseases, 679 (2008), pp. 1229-1234. 
[7] Kobelt G, Kasteng F. Access to innovative treatments in rheumatoid arthritis in Europe. 2009 October [cited 201020 September]. Available from:

<http://www.sciencedirect.com.proxy.library.uu.nl/science?_ob=RedirectURL\&_method=externObjLink\&_ ocator $=$ url \& issn $=01688510$ \& origin $=$ article \& zone=art page\& plusSign $=\% 2 \bar{B} \&$ targetURL $=$ http $\% 253 \bar{A}$ \%252F\%252Fwww.comparatorreports.se\%252FAccess\%25252520to\%25252520RA\%25252520Treatme nts\%252525200ctober\%252525202009.pdf>.

[8] P. Stolk, S.V. Belitser, H.G.M. Leufkens and E.R. Heerdink, Variable access to clopidogrel in a harmonized EU market. Value in Health, 115 (2008), pp. 989-995.

[9] C.Y. Lu, J. Ritchie, K.M. Williams and O.R. Day, Recent developments in targeting access to high cost medicines in Australia. Australia and New Zealand Health Policy, 2 (2005), p. 28.

[10] P. Emery and M. Buch, Treating rheumatoid arthritis with tumour necrosis factor alpha blockade. BMJ, 3247333 (2002), pp. 312-313.

[11] M. Richards, Extent and causes of international variations in drug usage. Secretary State of Health, (2010).

[12] B. Jonsson, G. Kobelt and J. Smolen, The burden of rheumatoid arthritis and access to treatment: uptake of new therapies. European Journal of Health Economics, 8 Suppl. 2 (2008), pp. S61-S86.

[13] E. Nolte, J. Newbould and A. Conklin, International variation in the usage of medicines. A review of the literature, RAND Corporation (2010).

[14] Miltenburger C, Günther OH, Justo N, Karampampa K, Texier-Richard B, Schweikert B. A survey of barriers to treatment access in rheumatoid arthritis in France, Germany, Italy, Spain and the UK. 2009 October 2009 [cited 201020 September]. Available from:

<http://www.sciencedirect.com.proxy.library.uu.nl/science?_ob=RedirectURL\&_method=externObjLink\&_I ocator $=$ url\&_issn $=01688510$ \&_origin=article\&_zone $=$ art_page\&_plusSign $=\% 2 \bar{B} \&$ targetURL_http $\% 253 \bar{A}$ \%252F\%252Fwww.comparatorreports.se\%252FRA\%25252520Barrier\%25252520Report_FINAL_050110 .pdf>..

[15] European Medicines Agency. EPAR Remicade [cited 2009 May]. Available from:

<http://www.sciencedirect.com.proxy.library.uu.nl/science?_ob=RedirectURL\&_method=externObjLink\&_I ocator $=$ url \& issn $=01688510$ \& origin=article \& zone $=$ art page \& plusSign $=\% 2 \bar{B} \&$ targetURL $=h \operatorname{ttp} \% 253 \bar{A}$ $\% 252 \mathrm{~F} \% 252 \mathrm{Fwww}$.emea.europa.eu\%252Fhumandocs\%252FHumans\%252FEPAR\%252Fremicade\%25 2Fremicade.htm>.

[16] J.S. Smolen and G. Steiner, Therapeutic strategies for rheumatoid arthritis. Nature Reviews Drug Discovery, 26 (2003), pp. 473-488.

[17] European Medicines Agency. EPAR Humira [cited 2009 May]. Available from: <http://www.sciencedirect.com.proxy.library.uu.nl/science?_ob=RedirectURL\&_method=externObjLink\&_I ocator $=$ url\&_issn $=01688510$ \&_origin=article\&_zone $=$ art_page\&_plusSign $=\% 2 \bar{B} \&$ targetURL=http $\% 253 \bar{A}$ \%252F\%252Fwww.emea.europa.eu\%252Fhumandocs\%252FHumans\%252FEPAR\%252Fhumira\%252F humira.htm>..

[18] European Medicines Agency. EPAR Enbrel [cited 2009 May 22]. Available from: <http://www.sciencedirect.com.proxy.library.uu.nl/science?_ob=RedirectURL\&_method=externObjLink\&_I ocator $=$ url\&_issn $=01688510$ \& origin=article\&_zone $=$ art_page\&_plusSign $=\% 2 \bar{B} \&$ targetURL $=h \operatorname{ttp} \% 253 \bar{A}$ $\% 252 \mathrm{~F} \% 252 \mathrm{Fwww}$.emea.europa.eu\%252Fhumandocs\%252FHumans\%252FEPAR\%252Fenbrel\%252Fe nbrel.htm>..

[19] Gesundheit Österreich (GÖG)/Austrian Health Institute, H.E.D. Pharmaceutical Pricing and Reimbursement Information - Country Reports. 2009 [cited 2010 August 22]. Available from: $<$ ttp://ppri.oebig.at/index.aspx? Navigation=r|2|1->..

[20] J.E. Fonseca, H. Canhão, P. Reis, M.J. Santos, J. Branco and A. Quintal, et al. Portuguese guidelines for the use of biological agents in rheumatoid arthritis, . Acta Reumatologica Portuguesa, 35 March (1) (2010), pp. 95-98

[21] Organisation for Economic Co-operation and Development. OECD Health Data 2010-Version: June 2010. 2009 [cited 2010 August]. Available from:

<http://www.sciencedirect.com.proxy.library.uu.nl/science?_ob=RedirectURL\&_method=externObjLink\& I ocator $=$ url\&_issn $=01688510$ \&_origin=article\&_zone=art_page\&_plusSign $=\% 2 \bar{B} \&$ targetURL=http $\% 253 \bar{A}$ \%252F\%252Fwww.irdes.fr\%252FEcoSante\%252FDownLoad\%252FOECDHealthData_FrequentlyReque stedData.xls>..

[22] Guidelines for Prescribing TNFalpha Blockers in Adults with Rheumatoid Arthritis, Irish Society of Rheumatology..

[23] Kwaliteitsinstituut voor de Gezondheidszorg CBO, Richtlijn: Diagnostiek en behandeling van reumatoïde artritis. 2009, Nederlandse Vereniging voor Reumatologie. p. $211 .$. 
Hoebert, J.M., Mantel-Teeuwisse, A.K., Dijk, L. van, Bijlsma, J.W.J., Leufkens, H.G.M. Do rheumatoid arthritis patients have equal access to treatment with new medicines? Tumour necrosis factor-alpha inhibitors use in four European countries. Health Policy: 2012, 104(1), 76-83

[24] World Health Organization. Collaborating Centre for Drug Statistics Methodology. ATC/DDD methodology [cited 200911 March]. Available from:

<http://www.sciencedirect.com.proxy.library.uu.nl/science?_ob=RedirectURL\&_method=externObjLink\&_I ocator $=$ url\&_issn $=01688510 \&$ origin $=$ article\&_zone $=$ art_page\&_plusSign $=\% 2 B$ \& _targetURL $=h \mathrm{htp} \% 253 \mathrm{~A}$ \%252F\%252Fwww.whocc.no\%252Fatc_ddd_methodology\%252Fpurpose_of_the_atc_ddd_system\%252 F>..

[25] World Health Organization. Collaborating Centre for Drug Statistics Methodology. DDD [cited 200910 March]. Available from:

<http://www.sciencedirect.com.proxy.library.uu.nl/science?_ob=RedirectURL\&_method=externObjLink\&_I ocator $=$ url\&_issn $=01688510$ \&_origin $=$ article\&_zone $=$ art_page\&_plusSign $=\% 2 \bar{B} \&$ targetURL=http $\% 253 \bar{A}$ \%252F\%252Fwww.whocc.no\%252Fddd\%252Fdefinition_and_general_considera\%252F>..

[26] M. Ronning, H.S. Blix, H. Strøm, E. Skovlund, M. Andersen and R. Vander Stichele, Problems in collecting comparable national drug use data in Europe: the example of antibacterials. European Journal of Clinical Pharmacology, 5812 (2003), pp. 843-849.

[27] World Health Organization. Collaborating Centre for Drug Statistics Methodology. ATC/DDD index [cited 2009 October]. Available from:

<http://www.sciencedirect.com.proxy.library.uu.nl/science?_ob=RedirectURL\&_method=externObjLink\&_I ocator $=$ url\&_issn $=01688510$ \&_origin=article\&_zone $=$ art_page\&_plusSign $=\% 2 \bar{B} \&$ targetURL=http $\% 253 \bar{A}$ $\% 252 \mathrm{~F} \% 25 \overline{2} \mathrm{Fwww}$.whocc.no\%252Fatcddd $\% \overline{2} 52 \mathrm{~F}>$..

[28] Eurostat. Population statistics [cited 2011 September]. Available from:

<http://www.sciencedirect.com.proxy.library.uu.nl/science?_ob=RedirectURL\&_method=externObjLink\&_I ocator $=$ url\&_issn $=01688510$ \&_origin=article\&_zone $=$ art_page\&_plusSign $=\% 2 \bar{B} \&$ targetURL=http $\% 253 \bar{A}$ \%252F\%252Fepp.eurostat.ec.europa.eu\%252Fportal\%252Fpage\%252Fportal\%252Feurostat\%252Fhom $\mathrm{e}>$..

\section{TABLES AND FIGURES}


Hoebert, J.M., Mantel-Teeuwisse, A.K., Dijk, L. van, Bijlsma, J.W.J., Leufkens, H.G.M. Do rheumatoid arthritis patients have equal access to treatment with new medicines? Tumour necrosis factor-alpha inhibitors use in four European countries. Health Policy: 2012, 104(1), 76-83
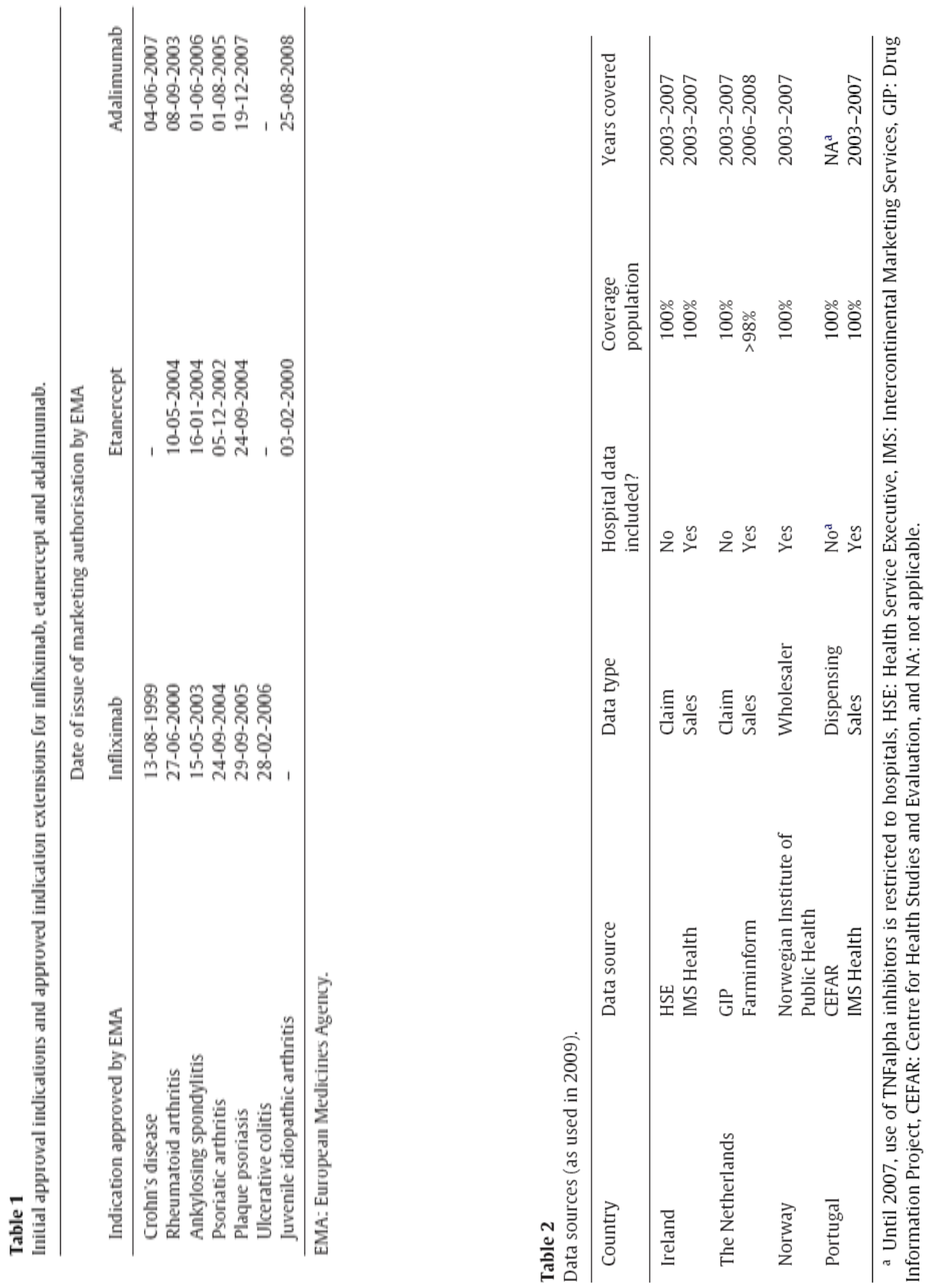
Hoebert, J.M., Mantel-Teeuwisse, A.K., Dijk, L. van, Bijlsma, J.W.J., Leufkens, H.G.M. Do rheumatoid arthritis patients have equal access to treatment with new medicines? Tumour necrosis factor-alpha inhibitors use in four European countries. Health Policy: 2012, 104(1), 76-83

Fig. 1. Utilisation of TNFalpha inhibitors in DDDs/1000 inhabitants/day between 2003 and 2007.

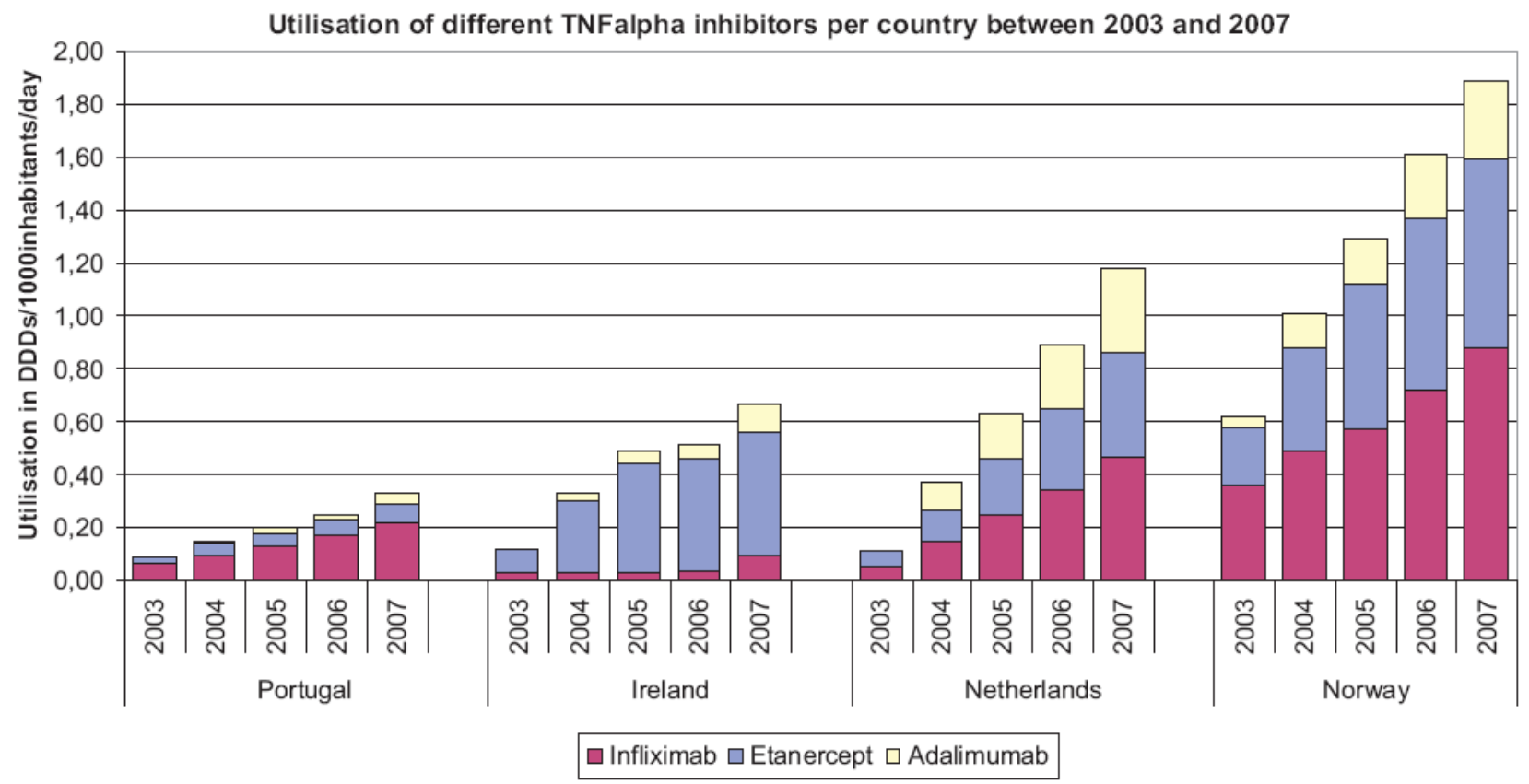

Fig. 1. Utilisation of TNFalpha inhibitors in DDDs/1000 inhabitants/day between 2003 and 2007. 
Hoebert, J.M., Mantel-Teeuwisse, A.K., Dijk, L. van, Bijlsma, J.W.J., Leufkens, H.G.M. Do rheumatoid arthritis patients have equal access to treatment with new medicines? Tumour necrosis factor-alpha inhibitors use in four European countries. Health Policy: 2012, 104(1), 76-83

Table 3

Launch dates and country characteristics (data for 2003 and 2007).

\begin{tabular}{|c|c|c|c|c|}
\hline & Norway & Netherlands & Ireland & Portugal \\
\hline \multicolumn{5}{|l|}{ Population characteristics } \\
\hline Population (millions) & $4.6-4.7$ & $16.2-16.4$ & $4.0-4.3$ & $10.4-10.6$ \\
\hline $\begin{array}{l}\text { Population aged } 65 \text { years and } \\
\text { over (\%) }\end{array}$ & $14.8-14.6$ & $13.8-14.6$ & $11.1-10.8$ & $16.7-17.3$ \\
\hline \multicolumn{5}{|l|}{ Production and expenditure } \\
\hline GDP per capita in US\$ & $38,294-53,802$ & $31,699-39,594$ & $34,512-44,381$ & $18,789-22,638$ \\
\hline $\begin{array}{l}\text { Health expenditure as a share } \\
\text { of GDP }(\%)\end{array}$ & $10-8.9$ & 9.8 & $7.3-7.6$ & $9.7-9.9^{\mathrm{a}}$ \\
\hline THE per capita US\$ PPP & $3837-4763$ & 3099-3837 & $2521-3424$ & $1823-2150^{\mathrm{a}}$ \\
\hline TPE per capita in US\$ PPP & $354-393$ & $346-430^{\mathrm{b}}$ & $381-609$ & $394-489$ \\
\hline \multicolumn{5}{|l|}{ Disease characteristics [7] } \\
\hline $\begin{array}{l}\text { Prevalence RA (per } 100 \\
\text { inhabitants) }\end{array}$ & 0.56 & 0.46 & 0.49 & 0.47 \\
\hline \multicolumn{5}{|l|}{ Launch dates } \\
\hline Infliximab (source: Centocor) & 1 June 2000 & 1 September 1999 & 20 January 2000 & 1 October 1999 \\
\hline Etanercept (source: Wyeth) & $14-12-2000$ & $15-05-2000$ & $01-08-2000$ & $13-07-2000$ \\
\hline Adalimumab (source: Abbott) & October 2003 & February 2004 & December 2003 & October 2003 \\
\hline \multicolumn{5}{|l|}{ Price information $(2004 / 2007)^{\mathrm{f}}$} \\
\hline $\begin{array}{l}\text { Infliximab } 100 \mathrm{mg} \text { (vial, } \\
\text { solution powder) }\end{array}$ & $0.99 / 1.01$ & 1.00 (ref) & 1.11/n.a. & $1.05 / 0.85$ \\
\hline $\begin{array}{l}\text { Adalimumab } 40 \mathrm{mg} \text { (prefilled } \\
\text { syringe) }\end{array}$ & $0.99 / 1.09$ & 1.00 (ref) & $1.02 / 1.00$ & $1.79 / 1.52$ \\
\hline $\begin{array}{l}\text { Etanercept } 25 \mathrm{mg} \text { (vial, } \\
\text { injection powder) }\end{array}$ & $1.06 / 1.08$ & 1.00 (ref) & $0.99 / 1.04$ & $0.99 / 0.95$ \\
\hline \multicolumn{5}{|c|}{ Initiation recommendations $[20,22]$} \\
\hline Trial of DMARD & One DMARD & One DMARD & $\begin{array}{l}\text { One DMARD for at least } \\
3 \text { months }\end{array}$ & $\begin{array}{l}\text { at least one DMARD for at } \\
\text { least } 3 \text { months }\end{array}$ \\
\hline $\begin{array}{l}\text { Disease activity level required } \\
\text { for initiation }\end{array}$ & Not specified & DAS28 $>3.2$ & DAS28 $>5.1$ & $\begin{array}{l}\text { DAS28 > } 3.2 \text { despite } \\
\text { treatment with DMARD }\end{array}$ \\
\hline \multicolumn{5}{|c|}{ Initial reimbursement decision date } \\
\hline Infliximab & d & $2001^{\mathrm{e}}$ & c & c \\
\hline Etanercept & d & $01-10-2000$ & 01-07-2000 & c \\
\hline Adalimumab & d & 01-01-2004 & $01-12-2003$ & c \\
\hline \multicolumn{5}{|c|}{ Reimbursement extents (September 2009) } \\
\hline Inpatient & $\begin{array}{l}\text { No co-payment } \\
\text { Unrestricted } \\
\text { reimbursement }\end{array}$ & $\begin{array}{l}\text { No co-payment } \\
\text { Unrestricted } \\
\text { reimbursement }\end{array}$ & $\begin{array}{l}\text { No co-payment } \\
\text { Reimbursement } \\
\text { restrictions is a individual } \\
\text { hospital decision }\end{array}$ & $\begin{array}{l}\text { No co-payment. } \\
\text { Reimbursement is } \\
\text { restricted to certain } \\
\text { indications }\end{array}$ \\
\hline Outpatient & No co-payment & $\begin{array}{l}\text { No co-payment } \\
\text { Reimbursement is } \\
\text { restricted to certain } \\
\text { indications and after failure } \\
\text { of at least two DMARDs }\end{array}$ & $\begin{array}{l}\text { Co-payment depends on } \\
\text { medical scheme. }\end{array}$ & $\begin{array}{l}\text { No outpatient use (until } \\
\text { 2007) }\end{array}$ \\
\hline
\end{tabular}

GDP: Gross Domestic Product, THE: Total Health Expenditure, TPE: Total Pharmaceutical Expenditure, DAS: Disease Activity Score, PPP: purchasing power parity, and n.a.: not available.

a Data for 2003 and 2006.

b For The Netherlands, no data was available for TPE per capita between 2003 and 2008. TPE per capita for this period was calculated by assuming a linear increase in TPE between 2002 and 2009, for which data was available.

${ }^{c}$ Until 2007: hospital only product and products under this classification are not required to undergo a reimbursement process - they can be prescribed in hospital from licensing date.

${ }^{d}$ The TNFalpha inhibitors are financed through the various Regional Health Authorities (hospitals) since June 1st, 2006.

e Before 2001 infliximab was a hospital only product and was not required to undergo a reimbursement process. The situation changed due to the insufficient production capacities of etanercept.

f Price information was retrieved from GÖG PPI System 2011. Ratios were calculated (with The Netherlands as reference, ratio $=1.00$ ) to express differences in ex-factory prices of similar formulations between countries. 
Hoebert, J.M., Mantel-Teeuwisse, A.K., Dijk, L. van, Bijlsma, J.W.J., Leufkens, H.G.M. Do rheumatoid arthritis patients have equal access to treatment with new medicines? Tumour necrosis factor-alpha inhibitors use in four European countries. Health Policy: 2012, 104(1), 76-83

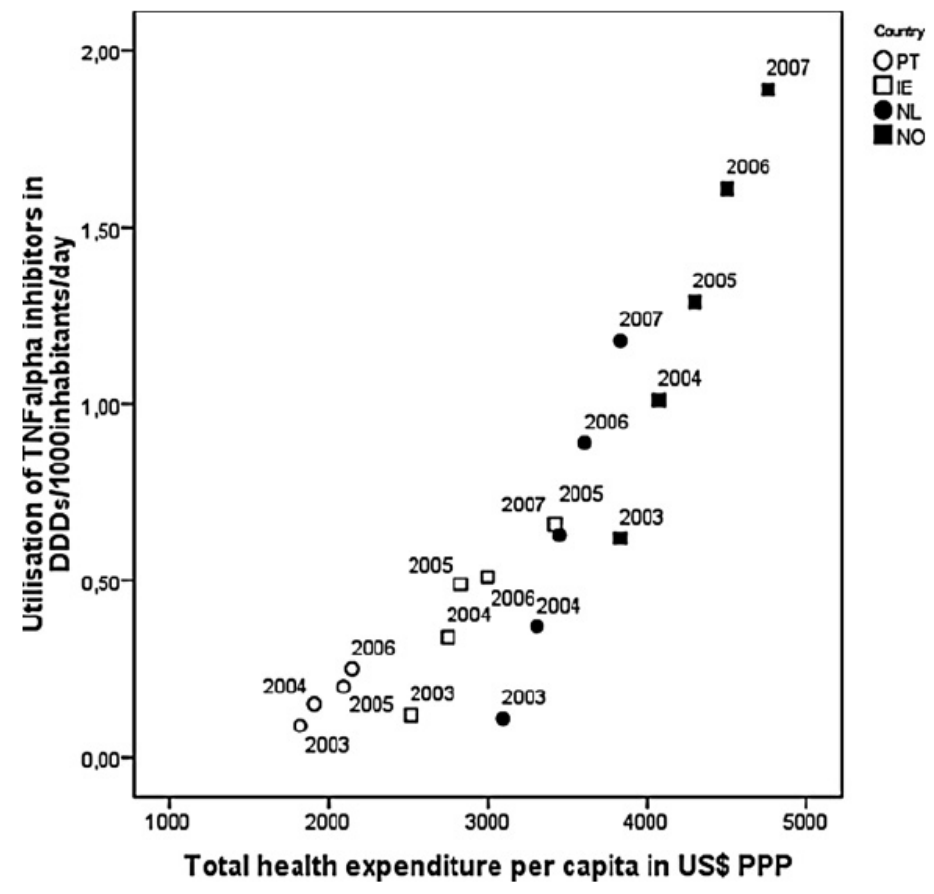

Fig. 2. Utilisation of TNFalpha inhibitors versus total health expenditures per capita between 2003 and 2007. PT: Portugal, IE: Ireland, NL: Netherlands, NO: Norway, PPP: purchasing power parity, and DDD: defined daily dose.

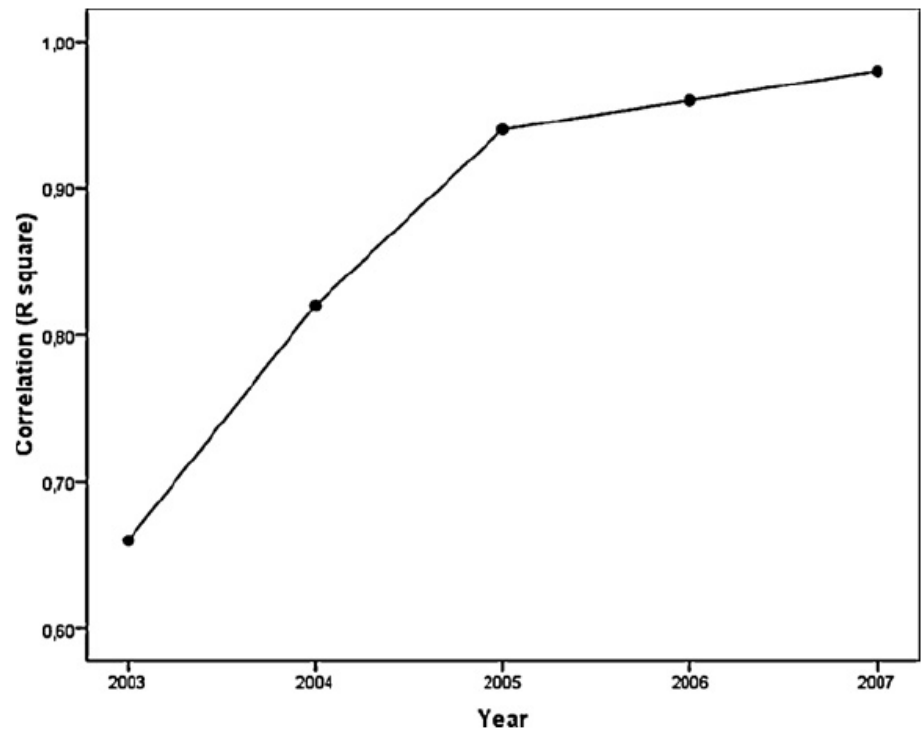

Fig. 3. Increase in correlation over time. 
Hoebert, J.M., Mantel-Teeuwisse, A.K., Dijk, L. van, Bijlsma, J.W.J., Leufkens, H.G.M. Do rheumatoid arthritis patients have equal access to treatment with new medicines? Tumour necrosis factor-alpha inhibitors use in four European countries. Health Policy: 2012, 104(1), 76-83

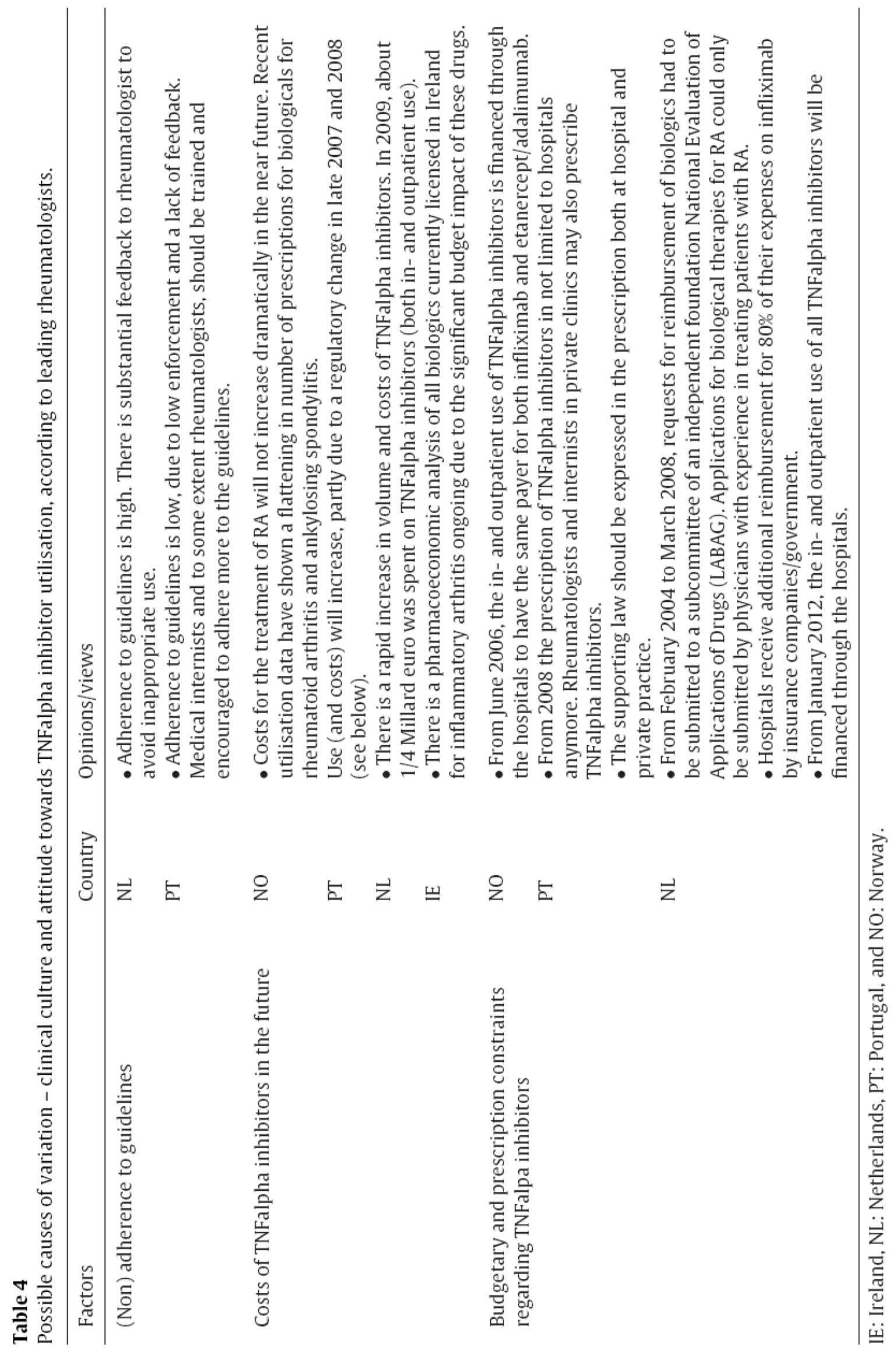

